\title{
Role of intraparotid node metastasis in mucoepidermoid carcinoma of the parotid gland
}

Xingyu Niu ${ }^{1 *}$, Qigen Fang ${ }^{2}$ and Fei Liu ${ }^{1}$

\begin{abstract}
s
Background: Prognostic factors for parotid mucoepidermoid carcinoma (MEC) usually include disease grade, tumor stage, node stage, perineural invasion, and lymphovascular invasion. But the role of intraparotid nodes (IPNs) remains unclear, therefore, the study aimed to analyze the significance of IPNs in predicting recurrence in parotid MEC.

Methods: One hundred and ninety patients were included for analysis finally. Data regarding demography, pathological characteristics, IPN metastasis, TNM stage, follow up was collected and evaluated. The recurrence-free survival (RFS) was the main study endpoint.

Results: A total of 47 (24.7\%) patients had IPN metastasis, and the IPN metastasis was significantly related to tumor stage, pathologic N stage, lymph-vascular invasion, perineural invasion, and disease grade. Recurrence occurred in 34 (17.9\%) patients. For patients without IPN metastasis, the 10-year RFS rate was $88 \%$, for patients with IPN metastasis, the 10-year RFS rate was $54 \%$, the difference was significant $(p<0.001)$. Further Cox model analysis confirmed the independence of IPN metastasis in predicting the prognosis.
\end{abstract}

Conclusion: The IPN metastasis is relatively common in parotid MEC, it is significantly related to tumor stage and disease grade, IPN metastasis means worse recurrence-free survival.

Keywords: Intraparotid node, Parotid cancer, Mucoepidermoid carcinoma, Recurrence, Prognosis

\section{Background}

Parotid gland cancer is an uncommon neoplasm [1], but according to their architectural and cytological features, there were 24 types of malignant tumors classified by The World Health Organization [2, 3], mucoepidermoid carcinoma (MEC) is the most common pathologic subtype, some clinic-pathologic variables, including histologic grade, lymphovascular and perineural invasion as well as tumor stage, have been well described to be associated with the prognosis in parotid MEC [4-6].

Because of the exceptional growth process, there are intraparotid nodes (IPNs) in the parotid gland [7], its prognostic value remains unclear [8-11]. The IPNs are classified into superficial and deep lobe nodes [12],

\footnotetext{
*Correspondence: niuxingyu@163.com

'Department of Oral Medicine, The First Affiliated hospital of Zhengzhou

University, Zhengzhou, People's Republic of China

Full list of author information is available at the end of the article
}

therefore the IPNs are significantly affected by different surgical procedures, compared to total parotidectomy, lateral or superficial parotidectomy has a lower probability to find all relevant IPNs, but in the above-mentioned researches [8-11], a certain number of procedures of lateral or superficial parotidectomy are included, therefore the exact IPN metastasis rate as well as its survival impact in patients with MEC remains unclear.

Therefore, the current study aimed to evaluate the IPN metastasis rate and the significance of IPN metastasis in predicting recurrence in parotid MEC.

\section{Methods}

Our study was approved by the Zhengzhou University institutional research committee, and an informed consent agreement for medical research before initial treatment was achieved for all participants, and all experiments were performed in accordance with the Declaration of Helsinki.

(C) The Author(s). 2019 Open Access This article is distributed under the terms of the Creative Commons Attribution 4.0 International License (http://creativecommons.org/licenses/by/4.0/), which permits unrestricted use, distribution, and 
Patients undergoing surgical treatment for primary parotid MEC during January 2001 and December 2017 were retrospectively tracked. Data regarding demography, pathological characteristics, TNM stage, IPN metastasis, and follow-up information was collected and assessed. The tumor stage and tumor grade were formulated based on the AJCC ${ }^{8 \text { th }}$ classification and the WHO 2017 classification, respectively. Ultrasound and CT or MRI examination was conducted for every patient, and total parotidectomy was conducted when malignant epithelial disease was supported by frozen section of the primary tumor.

The relationship between the clinical-pathologic variables and the IPN metastasis was assessed by the Chi-square test. The main study endpoint was the recurrence-free survival (RFS), and it was calculated by the Kaplan-Meier method (Log-rank test), the Cox proportional hazards method was used to analyze the factors which were significant in the univariable analysis to determine the independent risk factors for the RFS. All statistical analyses were performed by SPSS 20.0, and a $p<0.05$ was considered to be significant.

\section{Results}

One hundred and ninety patients (101 female and 89 male) were included for analysis, the mean age was 48.7 years with a range from 18 to 85 . Pathologic tumor stages of T1, T2, T3, and T4 presented in 27, 95,45 , and 23 cases, respectively. Neck metastatic node disease was found in 41 cases of the 62 patients undergoing a neck dissection. Negative (R0) and positive margin (R1/2) was achieved in 181 and 9 patients, respectively. Perineural and lymphovascular invasion was noted in 23 and 22 patients, respectively. Low grade MEC reported in 104 cases, intermediate grade in 62 cases, and high grade in 24 cases, .

A total of 47 (24.7\%) patients had IPN metastasis. As described in Table 1, pathologic N stage, tumor stage, perineural invasion, lymph-vascular invasion, and disease grade were significantly related to the IPN metastasis (all $p<0.05)$.

After a mean time of 71.1 months follow-up, adjuvant radiotherapy was performed in 65 patients, and recurrence occurred in 34 patients: 17 patients had local recurrence, 10 patients had neck recurrence, and 7 patients had both local and regional recurrence. The overall 10-year RFS rate was $79 \%$. In univariable analysis, tumor stage, IPN metastasis, perineural invasion, and lymphovascular invasion as well as disease grade were significantly associated with the recurrence (Table 2 , all $p<0.05$ ). The 10 -year RFS rate was $54 \%$ for patients with IPN metastasis, and $88 \%$ for patients without IPN metastasis, the difference was significant
Table 1 Association between intraparotid node metastasis and clinical-pathologic variables

\begin{tabular}{|c|c|c|c|}
\hline \multirow[t]{2}{*}{ Variables } & \multicolumn{2}{|c|}{ Intraparotid node metastasis } & \multirow[t]{2}{*}{$\mathrm{p}$} \\
\hline & Positive $(n=47)$ & Negative $(n=143)$ & \\
\hline \multicolumn{4}{|l|}{ Age } \\
\hline$\leq 50$ & 20 & 72 & \\
\hline$>50$ & 27 & 71 & 0.353 \\
\hline \multicolumn{4}{|l|}{ Sex } \\
\hline Female & 29 & 72 & \\
\hline Male & 18 & 71 & 0.176 \\
\hline \multicolumn{4}{|l|}{ Tumor stage } \\
\hline $\mathrm{T} 1+\mathrm{T} 2$ & 23 & 99 & \\
\hline $\mathrm{T} 3+\mathrm{T} 4$ & 24 & 44 & 0.012 \\
\hline \multicolumn{4}{|l|}{ p-Neck stage * } \\
\hline No & 6 & 15 & \\
\hline $\mathrm{N}+$ & 30 & 11 & 0.001 \\
\hline \multicolumn{4}{|c|}{ Perineural invasion } \\
\hline Yes & 11 & 12 & \\
\hline No & 36 & 131 & 0.006 \\
\hline \multicolumn{4}{|c|}{ Lymphovascular invasion } \\
\hline Yes & 11 & 11 & \\
\hline No & 36 & 132 & 0.003 \\
\hline \multicolumn{4}{|l|}{ Disease grade } \\
\hline Low & 12 & 92 & \\
\hline Intermediate & 24 & 38 & \\
\hline High & 11 & 13 & $<0.001$ \\
\hline
\end{tabular}

*: Patients undergoing neck dissection were analyzed

Table 2 Univariate analysis for recurrence in patients with primary parotid cancer

\begin{tabular}{ll}
\hline Variables & $p$ \\
\hline Age $(\leq 50$ vs $>50)$ & 0.520 \\
Sex (Female vs male) & 0.116 \\
Resection status (R0 vs R1/2) & 0.384 \\
Tumor stage (T1 + T2 vs T3 + T4) & 0.004 \\
Neck disease & 0.213 \\
Lymphovascular invasion & $<0.001$ \\
Perineural invasion & $<0.001$ \\
Disease grade & $<0.001$ \\
IPN* metastasis & $<0.001$ \\
Radiotherapy & 0.495 \\
\hline
\end{tabular}

* IPN: intraparotid node 


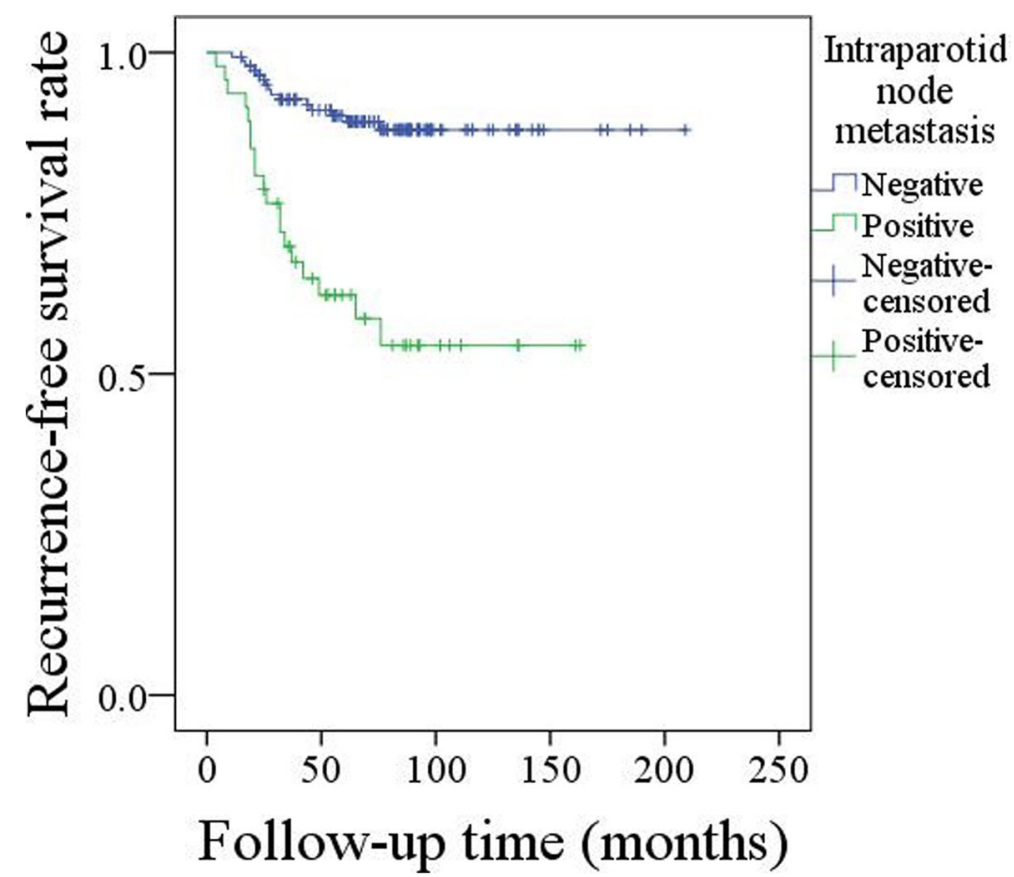

Fig. 1 Recurrence-free survival rate in patients with or without intraparotid node metastasis $(p<0.001)$

$(p<0.001)$ (Fig. 1). In Cox model analysis, IPN metastasis, lymphovascular invasion, and disease grade were independent prognostic factors for the RFS (Table 3, all $p<0.05$ ).

\section{Discussion}

Literature regarding the prognostic value of IPN metastasis was very few [8-11, 13-16]. Previous authors had reported the IPN metastasis rate ranged from 15 to $38 \%$, and the IPN metastasis was significantly related to TNM stage and disease grade [8-11,13-18], the finding was consistent with ours.

The IPN metastasis might affect the prognosis by two aspects. Firstly, lymph nodes existed in both lobes of the parotid gland, undiagnosed metastatic IPNs might be caused by non-total parotidectomy, and then recurrent

Table 3 Cox model for recurrence in patients with primary parotid cancers

\begin{tabular}{llll}
\hline Variables & $\operatorname{Exp}(\mathrm{B})$ & $95 \% \mathrm{Cl}$ & $\mathrm{p}$ \\
\hline Tumor stage & 1.470 & $0.646-3.344$ & 0.359 \\
Lymphovascular invasion & 9.576 & $4.375-20.959$ & $<0.001$ \\
Perineural invasion & 0.982 & $0.370-2.605$ & 0.970 \\
Disease grade & & & \\
Low & & & \\
Intermediate & 2.592 & $0.953-7.048$ & 0.062 \\
High & 3.478 & $1.120-10.798$ & 0.031 \\
IPN* metastasis & 2.357 & $1.163-4.776$ & 0.017 \\
\hline
\end{tabular}

*: IPN: intraparotid node disease might be expected owing to the residual disease. Therefore, total parotidectomy was suggested for all parotid cancer patients by previous authors [15]. The high 10 -year RFS rate in current study came into our attention, it was better than previous researches $[8,11]$, the favorable outcome might be partially explained by our routine total parotidectomy. Another potential explanation was that high grade disease only accounted for less than $15 \%$ in our sample, and previous authors had described the disease grade was an important prognostic factor in parotid cancers [17].

Secondly, owing to the lymphatic system in head and neck area, the IPN might acted as sentinel role for finding early neck metastasis. Although Klussmann et al. [8] described pathologic neck metastasis was detected in only $33.3 \%$ of the patients with positive IPNs, both Lim et al. [12] and Nisa et al. [13] reported there was relatively high reliability of IPN metastasis in predicting neck metastasis. The viewpoint was also supported by our finding.

Risk factors for recurrence in parotid cancers had been frequently analyzed. Reported predictors included higher TNM stage, perineural invasion, lymphovascular invasion, high disease grade [13-22]. But the value of IPN metastasis remained unclear. Lim et al. [10] reported locoregional recurrence was more likely to occur in patients with cNO neck but IPN metastasis than patients without IPN metastasis. Klussmann et al. [8] presented there was additional risk associated with the IPN involvement for tumor recurrence. Nisa et al. [11] 
described patients with IPN metastasis had poorer disease control. However, the three studies were limited to small sample size, and also a considerable number of patients had not undergone total parotidectomy, there might be undiagnosed IPNs. In current study, all patients underwent an total parotidectomy, it made our result more accurate, our results presented IPN metastasis was related to worse disease control, all the findings revealed that IPN metastasis carried higher risk of recurrence [23].

Association between adjuvant radiotherapy and survival benefit had been widely evaluated. In a large National Cancer Database study, Safdieh et al. [24] reported adjuvant radiotherapy improved overall survival in 4068 patients with salivary gland cancer. Similar finding was also described by Lee et al. [25]. But in current study, we failed to note there is positive relationship between radiotherapy and improved RFS. In another paper by Erovic et al. [26], the authors also presented that adjuvant radiotherapy did not significantly increase disease control in parotid cancers. More studies were required to assess the role of radiotherapy on predicting the survival in parotid cancers.

\section{Conclusions}

In summary, the overall IPN metastasis rate in parotid MEC was $24.7 \%$, it was significantly affected by tumor stage and disease grade. Moreover, the IPN metastasis was independently related to two-fold risk for recurrence, more adjuvant intervention was needed if there was IPN metastasis.

\section{Abbreviations}

IPN: intraparotid node; MEC: mucoepidermoid carcinoma; RFS: recurrencefree survival

\section{Acknowledgements}

None declared.

\section{Funding}

This study was not funded by any outside source.

\section{Availability of data and materials}

All data generated or analyzed during this study are included in this published article. And the primary data could be achieved from the corresponding author.

\section{Authors' contributions}

Study design and manuscript writing: N-XY. Studies selecting and data analysis: N-XY, LF and F-QG. Study quality evaluating: N-XY and F-QG. Manuscript revising: $\mathrm{N}-\mathrm{XY}$. All authors have read and approved the final manuscript.

\section{Ethics approval and consent to participate}

Our study was approved by the Zhengzhou University institutional research committee, and an informed consent agreement for medical research before initial treatment was achieved for all participants, and all experiments were performed in accordance with the Declaration of Helsinki.

\section{Consent for publication}

All the material came from our cancer center, and the publish consent have been obtained from all the patients.

\section{Competing interests}

The authors declare that they have no competing interests.

\section{Publisher's Note}

Springer Nature remains neutral with regard to jurisdictional claims in published maps and institutional affiliations.

\section{Author details}

${ }^{1}$ Department of Oral Medicine, The First Affiliated hospital of Zhengzhou University, Zhengzhou, People's Republic of China. ${ }^{2}$ Department of Head Neck and Thyroid, Affiliated Cancer Hospital of Zhengzhou University, Henan Cancer Hospital, Zhengzhou, China.

Received: 11 October 2018 Accepted: 24 April 2019

Published online: 03 May 2019

\section{References}

1. Terhaard CH, Lubsen H, Van der Tweel I. Salivary gland carcinoma: independent prognostic factors for locoregional control, distant metastases, and overall survival: results of the Dutch head and neck oncology cooperative group. Head Neck. 2004;26:681-92.

2. Barnes LEJRP, Sidransky D. World Health Organization classification of tumours. Pathology and genetics of head and neck tumours. IARC. IARC: Lyon; 2005.

3. Barnes LEJ, Reichart P, Sidransky D. World Health Organization classification of tumours. Pathology and genetics of head and neck tumours. IARC. IARC: Lyon; 2005.

4. Szewczyk M, Golusiński P, Pazdrowski J, Pieńkowski P, Marszałek S, Sygut J, Golusiński W. Patterns of treatment failure in salivary gland cancers. Rep Pract Oncol Radiother. 2018:23:260-5.

5. Nisa L, Borner U, Dür C, Arnold A, Giger R. Recurrent parotid gland carcinoma: how effective is salvage surgery? Eur Arch Otorhinolaryngol. 2018;275:507-13。

6. Scherl C, Kato MG, Erkul E, Graboyes EM, Nguyen SA, Chi AC, Morgan PF, Day TA. Outcomes and prognostic factors for parotid acinic cell carcinoma: a National Cancer Database study of 2362 cases. Oral Oncol. 2018:82:53-60.

7. Pisani P, Ramponi A, Pia F. The deep parotid lymph nodes: an anatomical and oncological study. J Laryngol Otol. 1996;110:148-50.

8. Klussmann JP, Ponert T, Mueller RP, Dienes HP, Guntinas-Lichius O. Patterns of lymph node spread and its influence on outcome in resectable parotid cancer. Eur J Surg Oncol. 2008;34:932-7.

9. Lau VH, Aouad R, Farwell DG, Donald PJ, Chen AM. Patterns of nodal involvement for clinically NO salivary gland carcinoma: refining the role of elective neck irradiation. Head Neck. 2014;36:1435-9.

10. Lim CM, Gilbert MR, Johnson JT, Kim S. Clinical significance of intraparotid lymph node metastasis in primary parotid cancer. Head Neck. 2014:36:1634-7.

11. Nisa L, Salmina C, Dettmer MS, Arnold A, Aebersold DM, Borner U, Giger R. Implications of intraglandular lymph node metastases in primary carcinomas of the parotid gland. Laryngoscope. 2015;125:2099-106.

12. Sönmez Ergün $S$, Gayretli O, Büyükpınarbaşlı N, Yıldız K, Gürses IA, Avşar A, Cavlak M. Determining the number of intraparotid lymph nodes: postmortem examination. J Craniomaxillofac Surg. 2014;42:657-60.

13. Lima RA, Tavares MR, Dias FL, Kligerman J, Nascimento MF, Barbosa MM, Cernea CR, Soares JR, Santos IC, Salviano S. Clinical prognostic factors in malignant parotid gland tumors. Otolaryngol Head Neck Surg. 2005;133: 702-8.

14. Shinomiya H, Otsuki N, Yamashita D, Nibu K. Patterns of lymph node metastasis of parotid cancer. Auris Nasus Larynx. 2016;43:446-50.

15. Stenner M, Molls C, Luers JC, Beutner D, Klussmann JP, Huettenbrink KB. Occurrence of lymph node metastasis in early-stage parotid gland cancer. Eur Arch Otorhinolaryngol. 2012;269:643-8.

16. Stodulski D, Mikaszewski B, Majewska H, Wiśniewski P, Stankiewicz C. Probability and pattern of occult cervical lymph node metastases in primary parotid carcinoma. Eur Arch Otorhinolaryngol. 2017;274:1659-64.

17. Rajasekaran K, Stubbs V, Chen J, Yalamanchi P, Cannady S, Brant J, Newman J. Mucoepidermoid carcinoma of the parotid gland: a National Cancer Database study. Am J Otolaryngol. 2018;39:321-6.

18. Armstrong JG, Harrison LB, Thaler $\mathrm{HT}$, The indications for elective treatment of the neck in cancer of the major salivary glands. Cancer. 1992;69:615-9. 
19. Shi S, Fang Q, Liu F, Zhong M, Sun C. Prognostic factors and survival rates for parotid duct carcinoma patients. J Craniomaxillofac Surg. 2014;42:1929-31.

20. Zbären P, Schüpbach J, Nuyens M, Stauffer E, Greiner R, Häusler R. Carcinoma of the parotid gland. Am J Surg. 2003;186:57-62.

21. Niu X. Sarcomatoid carcinoma in the parotid gland: a review of 30 years of experience. Laryngoscope. 2018 [Epub ahead of print. https://doi.org/10. 1002/lary.27474.

22. Fang $Q$, Liu F, Seng D. Oncologic outcome of parotid mucoepidermoid carcinoma in pediatric patients. Cancer Manag Res. 2019;11:1081-5.

23. Feng Y, Liu F, Cheng G, Fang Q, Niu X, He W. Significance of intraparotid node metastasis in predicting local control in primary parotid cancer. Laryngoscope. 2018. https://doi.org/10.1002/lary.27701.

24. Safdieh J, Givi B, Osborn V, Lederman A, Schwartz D, Schreiber D. Impact of adjuvant radiotherapy for malignant salivary gland tumors. Otolaryngol Head Neck Surg. 2017;157:988-94

25. Lee A, Givi B, Osborn WW, Schwartz D, Schreiber D. Patterns of care and survival of adjuvant radiation for major salivary adenoid cystic carcinoma. Laryngoscope. 2017;127:2057-62.

26. Erovic BM, Shah MD, Bruch G, Johnston M, Kim J, O'Sullivan B, PerezOrdonez B, Weinreb I, Atenafu EG, de Almeida JR, Gullane PJ, Brown D, Gilbert RW, Irish JC, Goldstein DP. Outcome analysis of 215 patients with parotid gland tumors: a retrospective cohort analysis. J Otolaryngol Head Neck Surg. 2015;44:55.

Ready to submit your research? Choose BMC and benefit from:

- fast, convenient online submission

- thorough peer review by experienced researchers in your field

- rapid publication on acceptance

- support for research data, including large and complex data types

- gold Open Access which fosters wider collaboration and increased citations

- maximum visibility for your research: over $100 \mathrm{M}$ website views per year

At $\mathrm{BMC}$, research is always in progress.

Learn more biomedcentral.com/submissions 